\title{
Pemodelan Regresi Nonparametrik Spline Linear Persentase Penduduk Miskin di Kalimantan
}

\author{
Wianita Noviani $^{1}$, Sifriyani², Ika Purnamasari ${ }^{3}$ \\ ${ }^{1}$ Laboratorium Statistika Ekonomi dan Bisnis, FMIPA Universitas Mulawarman \\ 2,3 Program Studi Statistika, Jurusan Matematika, FMIPA Universitas Mulawarman \\ *Email korespondensi: novianiwianita@gmail.com
}

\begin{abstract}
Abstrak
Kemiskinan merupakan masalah sosial yang dihadapi hampir di setiap negara. Berdasarkan data BPS yang dipublikasikan tahun 2018, Provinsi Kalimantan Timur memiliki jumlah penduduk miskin sebanyak 222,39 ribu jiwa atau sekitar 6,06 persen. Pada Maret 2018, jumlah penduduk miskin sebanyak 218,90 ribu jiwa atau sekitar 6,03 persen yang artinya jumlah penduduk miskin meningkat secara absolut 3,49 ribu orang, hal ini menyebabkan persentase penduduk miskin meningkat 0,03 persen. Dalam penelitian ini diidentifikasi faktor-faktor yang mempengaruhi persentase penduduk miskin dengan menggunakan model regresi nonparametrik spline linier. Data yang digunakan dalam penelitian ini adalah data dari Badan Pusat Statistik (BPS) di 5 provinsi di Kalimantan. Pada metode regresi spline linier nonparametrik menggunakan titik simpul optimal berdasarkan nilai GCV terkecil. Hasil penelitian diperoleh nilai R2 sebesar $\mathbf{7 4 , 4 8 \%}$ yang menunjukkan bahwa model yang dibentuk layak digunakan untuk memodelkan pola data dan terdapat 5 variabel yang berpengaruh signifikan terhadap Persentase Penduduk Miskin yaitu Laju Pertumbuhan Penduduk, Rata-rata Lama Sekolah. , Tingkat Harapan Sekolah Tua, Tingkat Pengangguran Terbuka, Tingkat Partisipasi Angkatan Kerja.
\end{abstract}

Kata kunci: algoritma, persamaan fuzzy nonlinear, modifikasi Newton-Raphson.

\begin{abstract}
Poverty is a social problem faced in almost every country. Based on BPS data published in 2018, East Kalimantan Province has a population of poor people of 222.39 thousand people or around 6.06 percent. In March 2018, the number of poor people was 218.90 thousand people or about 6.03 percent, which means the number of poor people had increased by an absolute 3.49 thousand people, this caused the percentage of poor people to rise $\mathbf{0 . 0 3}$ percent. In this study identified factors that influence the percentage of poor population using a linear spline nonparametric regression model. The data used in this study are data from the Central Statistics Agency (BPS) in 5 provinces in Kalimantan. In the nonparametric linear spline regression method using the optimal knot point based on the smallest GCV value. The results obtained an $R^{2}$ value of $\mathbf{7 4 . 4 8 \%}$ which shows that the model formed is feasible to be used to model the data pattern and there are 5 variables that have a significant effect on the Percentage of Poor Population, namely Population Growth Rate, School Length Average, School Old School Expectancy Rate, Level Open Unemployment, Labor Force Participation Rate.
\end{abstract}

Keywords: Nonparametric Regression, Spline Linear, Percentage of Poor Population, Knots, GCV.

1. Pendahuluan

Kemiskinan merupakan permasalahan sosial yang dihadapi hampir disetiap negara. Kemiskinan tidak hanya dihadapi oleh pemerintah pusat akan tetapi juga menjadi permasalahan serius bagi pemerintah daerah. Persoalan kemiskinan yang dihadapi pemerintah erat dengan rendahnya pendapatan sehingga tidak dapat memenuhi kebutuhan pokoknya

Pulau Kalimantan merupakan salah satu pulau yang memiliki sumber daya paling banyak di Indonesia. Salah satu provinsi yang ada di Pulau Kalimantan adalah Provinsi Kalimantan Timur. Berdasarkan data BPS pada bulan September tahun 2018, Provinsi Kalimantan Timur memiliki jumlah penduduk miskin sebanyak 222,39 ribu jiwa atau sekitar 6,06 persen. Pada bulan Maret tahun 2018, jumlah penduduk miskin sebanyak 218,90 ribu jiwa atau sekitar 6,03 persen yang artinya jumlah penduduk miskin secara absolut bertambah 3,49 ribu jiwa, hal ini mengakibatkan persentase penduduk miskin naik 0,03 persen.

Beberapa penelitian sebelumnya yang menggunakan regresi nonparametrik Spline, yaitu Analisis FaktorFaktor yang Mempengaruhi Tingkat Pengangguran Terbuka di Kalimantan Menggunakan Regresi 
Nonparametrik Spline Truncated [1], Nonparametric Geographically Weighted Regression dengan Pendekatan Spline Truncated pada Data Produktivitas Tanaman Padi [2], Evaluasi Faktor yang Mempengaruhi Laju Pertumbuhan Ekonomi di Kalimantan Menggunakan Regresi Nonparametrik Spline dengan Pembobot Geografis (Millah et al, 2019), dan Pemodelan Regresi Nonparametrik Spline Truncated dan Aplikasinya Pada Indeks Pembangunan Manusiadi Pulau Kalimantan [3].

Berdasarkan uraian diatas, hal ini mendorong peneliti untuk meneliti tentang regresi nonparametrik spline beserta inferensi yang terkait dalam model tersebut. Data yang digunakan adalah persentase penduduk miskin tahun 2017 di Kalimantan sebagai variabel respon dan beberapa variabel prediktor yang diduga mempunyai pengaruh terhadap persentase penduduk miskin. Metode yang digunakan untuk menyelesaikan masalah pemodelan dalam penelitian ini adalah regresi nonparametrik spline truncated.

\section{Pendahuluan}

Regresi nonparametrik merupakan suatu metode yang digunakan untuk mengetahui pengaruh hubungan variabel prediktor terhadap variabel respon dimana bentuk pola (kurva regresi) data tidak diketahui atau tidak membentuk suatu pola tertentu. Salah satu metode estimasi regresi nonparametrik adalah spline. Spline merupakan potongan-potongan polinomial yang memiliki sifat tersegmen (piecewise polynomial) pada titik knot. [4].

Fungsi spline truncated univariabel dengan derajat $m$ dan titik knot pada titik $K_{1}, K_{2}, \ldots, K_{y}$ dituliskan seperti Persamaan (1) berikut:

$$
f(x)=\beta_{0}+\beta_{1} x+\sum_{k=1}^{r} \beta_{1+k}\left(x-K_{k}\right)_{+}^{m}
$$

dengan fungsi truncated seperti pada Persamaan (2) berikut:

$$
\left(x-K_{k}\right)_{+}^{m}= \begin{cases}\left(x-K_{k}\right)_{+}^{m}, x \geq K_{k} \\ 0 & x<K_{k}\end{cases}
$$

\subsection{Pemilihan Titik Knot Optimal}

Estimasi kurva regresi nonparametrik Spline dapat dilakukan dengan mencari model optimal yang diperoleh dengan memilih titik knot optimal. Titik knot merupakan titik perpaduan bersama dimana ada perubahan perilaku fungsi pada interval yang berlainan. Salah satu metode yang dapat digunakan untuk memilih titik knot optimal adalah Generalized Cross Validation (GCV) [4]. Dengan nilai GCV tersebut akan dipilih nilai GCV terkecil [5]. Fungsi GCV dapat dituliskan seperti Persamaan (3) berikut:

$$
\begin{aligned}
& \operatorname{GCV}\left(K_{1}, K_{2, \ldots,} K_{y}\right)=\frac{\operatorname{MSE}\left(K_{1}, K_{2, \ldots,} K_{y}\right)}{n^{-1}\left(\operatorname{tr}\left[I-A\left(K_{1}, K_{2, \ldots y} K_{y}\right)\right]\right)^{2}} \\
& =\frac{n^{-1}(y-X \widehat{\boldsymbol{\beta}})^{t}(y-X \widehat{\boldsymbol{\beta}})}{n^{-1}\left(\operatorname{tr}\left[I-A\left(K_{1}, K_{2, \ldots, K_{\gamma}}\right)\right]\right)^{2}}
\end{aligned}
$$

dimana I adalah matriks identitas dan matriks $\boldsymbol{A}\left(K_{1,} K_{2, \ldots,} K_{\mathrm{\gamma}}\right)=\boldsymbol{X}\left(\boldsymbol{X}^{p} \boldsymbol{X}\right)^{-1} \boldsymbol{X}^{s}$.

Pada himpunan klasik, nilai keanggotaan hanya memasangkan nilai 0 dan 1 untuk unsur-unsur pada semesta pembicaraan, yang menyatakan anggota atau bukan anggota [2]. Jika $X$ adalah himpunan semesta, maka nilai keanggotaan untuk himpunan $A$ adalah fungsi $\mu_{A}(x): X \rightarrow\{0,1\}$ dengan

$$
\mu_{A}(x)= \begin{cases}1_{x} & \text { jika } x \in A \\ 0, & \text { jika } x \notin A\end{cases}
$$

\subsection{Pengujian Signifikansi Parameter Model Serentak}

Sama halnya dengan regresi parametrik, pengujian signifikansi parameter secara serentak pada regresi nonparametrik Spline digunakan untuk mengetahui semua parameter secara serentak (bersama-sama) signifikan terhadap variabel respon atau tidak [6]. Jika pada pengujian ini diperoleh keputusan tolak $H_{0}$, maka akan dilanjutkan dengan pengujian secara parsial dimana orde yang digunakan adalah orde linier, $p$ menunjukkan banyaknya variabel prediktor, $r$ menunjukkan banyaknya knot, $n$ menunjukkan banyaknya observasi. $H_{0}: \beta_{11}=\beta_{12}=\cdots=\beta_{p(1+\gamma)}=0$

(tidak ada parameter yang signifikan secara serentak terhadap variabel respon) $H_{1}$ a minimal ada satu $\beta_{j(1+k)} \neq 0, j=1,2, \ldots, p$ dan $k=1,2, \ldots, r$ 
(minimal ada satu parameter yang signifikan terhadap variabel respon secara serentak)

Taraf Signifikansi

Daerah Penolakan

$$
\begin{aligned}
& : \alpha \\
& \left.\left.: \text { Tolak } H_{0} \text { jika } F>F_{\alpha u(p(1+r))}(n-(p(1+r))-1)\right)\right\}
\end{aligned}
$$

Statistik Uji

$$
F=\frac{M S R}{M S E}
$$

\subsection{Pengujian Signifikansi Parameter Model Parsial}

Sama halnya dengan regresi parametrik, uji signifikansi parameter secara parsial (individu) dilakukan untuk mengetahui parameter mana yang signifikan terhadap variabel respon [7]. Berikut adalah pengujian yang dilakukan dimana orde yang digunakan adalah orde linier, $p$ menunjukkan banyak variabel prediktor, $r$ menunjukkan banyaknya knot, dan $n$ menunjukkan banyaknya observasi.

$H_{0:} \beta_{j(1+k)}=0$ (Parameter tidak signifikan secara individu terhadap variabel respon)

$H_{1:} \beta_{j\{(1+k)} \neq 0$ (Parameter signifikan secara individu terhadap variabel respon)

Taraf Signifikansi

Daerah Penolakan

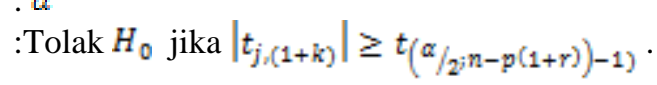

Statistik Uji

$$
t_{\text {hitung }}=\frac{\hat{\beta}_{i(1+k)}}{\operatorname{se}\left(\hat{\beta}_{j(1+k)}\right)}
$$

dimana $\operatorname{se}\left(\hat{\beta}_{\tilde{M}(1+k)}\right)$ merupakan standar error $\hat{\beta}_{j(1+k)}$ yang dapat diperoleh dari $s e\left(\hat{\beta}_{\tilde{I}(1+k)}\right)=\sqrt{\operatorname{var}\left(\hat{\beta}_{j(1+k)}\right)}$ dimana $\operatorname{var}\left(\hat{\beta}_{j(1+\mathbb{N}}\right)$ letaknya pada diagonal matriks varians covarians $\hat{\beta}_{j(1+k)}$ dengan $j=1,2, \ldots p$ dan $k=1,2, \ldots r r$. Dari hasil pengujian ini akan didapatkan nilai koefisien determinasi $\left(R^{2}\right)$ yang merupakan proporsi variansi total variabel respon yang dapat dijelaskan oleh sekian banyak variabel prediktor yang digunakan didalam model. Suatu model dapat dikatakaan baikjika nilai $\left(R^{2}\right)$ yang diperoleh cukup tinggi. Nilai $\left(R^{2}\right)$ dapat dihitung dengan rumus pada Persamaan (2.17) berikut:

$$
R^{2}=\frac{S S R}{S S T}=\frac{\sum_{i=1}^{n}\left(\bar{Y}_{1}-\bar{Y}\right)^{2}}{\sum_{i=1}^{n}\left(Y_{i}-\bar{Y}\right)^{2}}
$$

\subsection{Sumber Data}

Data pada penelitian ini merupakan data sekunder yang diambil pada website resmi Badan Pusat Statistik (BPS) Kalimantan Timur, Kalimantan Tengah, Kalimantan Selatan, Kalimantan Barat dan Kalimantan Utara pada tahun 2017. Adapun variabel-variabel pada penelitian terdapat sebanyak 1 variabel respon dan 5 variabel prediktor. Variabel responnya ialah Persentase Penduduk Miskin dan variabel prediktornya ialah Laju Pertumbuhan Penduduk, Rata-Rata Lama Sekolah, Angka Harapan Lama Sekolah, Tingkat Partisipasi Angkatan Kerja dan Tingkat Pengangguran Terbuka.

\section{Hasil dan Pembahasan}

\subsection{Scatteplot}

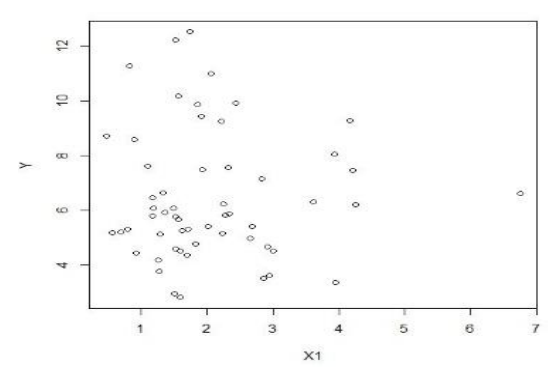

\section{Gambar 1 Scatterplot Persentase Warga Miskin dengan Laju Pertumbuhan Penduduk}

Persentase Penduduk Miskin $(y)$ diduga dipengaruhi oleh Laju Pertumbuhan Penduduk $\left(x_{1}\right)$. Scatterplot antara Persentase Penduduk Miskin $(y)$ diduga dipengaruhi oleh Laju Pertumbuhan Penduduk $\left(x_{1}\right)$ terlihat pola datanya tidak mengikuti pola data tertentu seperti pada Gambar 1. Oleh sebab itu, dapat digunakan metode regresi nonparametrik spline truncated. 


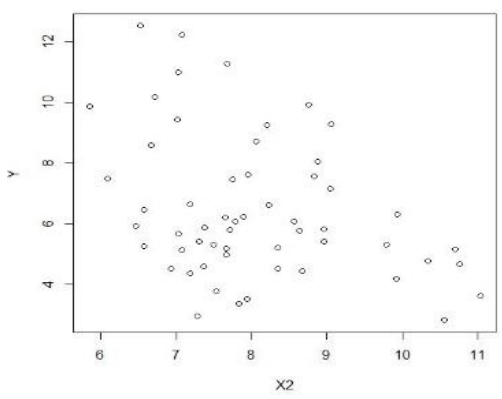

Gambar 2 Scatterplot Persentase Warga Miskin dengan Rata-Rata Lama Sekolah

Persentase Penduduk Miskin $(y)$ diduga dipengaruhi oleh Rata-Rata Lama Sekolah $\left(x_{2}\right)$. Scatterplot antara Persentase Penduduk Miskin (y) diduga dipengaruhi oleh Rata-Rata Lama Sekolah $\left(x_{2}\right)$ terlihat pola datanya tidak mengikuti pola data tertentu seperti pada Gambar 2. Oleh sebab itu, dapat digunakan metode regresi nonparametrik spline truncated.

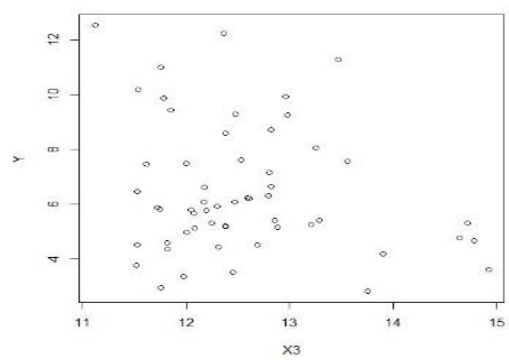

Gambar 3 Scatterplot Persentase Warga Miskin dengan Angka Harapan Lama Sekolah

Persentase Penduduk Miskin (y) diduga dipengaruhi oleh Angka Harapan Lama Sekolah $\left(x_{a}\right)$. Scatterplot antara Persentase Penduduk Miskin $(y)$ diduga dipengaruhi oleh Angka Harapan Lama Sekolah $\left(x_{a}\right)$ terlihat pola datanya tidak mengikuti pola data tertentu seperti pada Gambar 3. Oleh sebab itu, dapat digunakan metode regresi nonparametrik spline truncated.

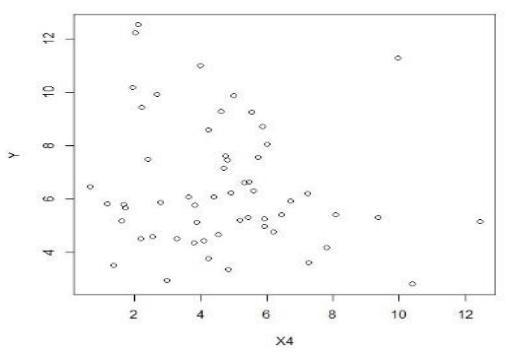

Gambar 4 Scatterplot Persentase Warga Miskin dengan Tingkat Partisipasi Angkatan Kerja

Persentase Penduduk Miskin $(y)$ diduga dipengaruhi oleh Tingkat Partisipasi Angkatan Kerja $\left(x_{4}\right)$. Scatterplot antara Persentase Penduduk Miskin (y) diduga dipengaruhi oleh Tingkat Partisipasi Angkatan Kerja $\left(x_{4}\right)$ terlihat pola datanya tidak mengikuti pola data tertentu seperti pada Gambar 4. Oleh sebab itu, dapat digunakan metode regresi nonparametrik spline truncated

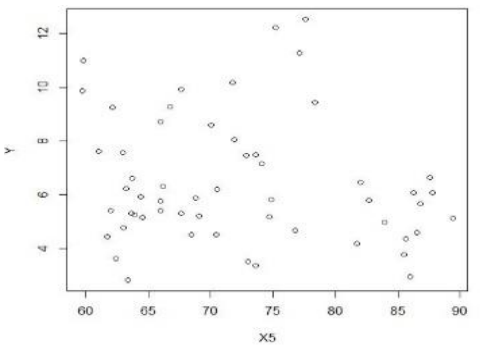

Gambar 5 Scatterplot Persentase Warga Miskin dengan Tingkat Pengangguran Terbuka 
Persentase Penduduk Miskin $(y)$ diduga dipengaruhi oleh Tingkat Pengangguran Terbuka $\left(x_{5}\right)$. Scatterplot antara Persentase Penduduk Miskin (y) diduga dipengaruhi oleh Tingkat Pengangguran Terbuka $\left(x_{5}\right)$ terlihat pola datanya tidak mengikuti pola data tertentu seperti pada Gambar 5. Oleh sebab itu, dapat digunakan metode regresi nonparametrik spline truncated.

\subsection{Titik Knot Optimal}

Tabel 1 Titik Knot Optimal

\begin{tabular}{|c|c|c|c|c|c|c|}
\hline $\begin{array}{c}\text { Variabel } \\
\text { Prediktor }\end{array}$ & $\begin{array}{c}\text { Satu } \\
\text { Knot }\end{array}$ & \multicolumn{2}{|c|}{ Dua Knot } & \multicolumn{3}{c|}{$\begin{array}{c}\text { Tiga } \\
\text { Knot }\end{array}$} \\
\hline$x_{1}$ & 0,6 & 3,5 & 4,1 & 1,3 & 3,5 & 4,1 \\
\hline$x_{2}$ & 5,9 & 8,4 & 8,9 & 6,6 & 8,4 & 8,9 \\
\hline$x_{3}$ & 11,2 & 12,9 & 13,4 & 11,6 & 12,9 & 13,3 \\
\hline$x_{4}$ & 0,9 & 6,4 & 7,6 & 2,3 & 6,3 & 7,6 \\
\hline$x_{5}$ & 60,3 & 74 & 77,1 & 63,8 & 74 & 77,1 \\
\hline GCV & 5,37 & \multicolumn{3}{|c|}{4,91} & \multicolumn{5}{|c|}{4,9} \\
\hline
\end{tabular}

Berdasarkan Tabel 1 di atas dapat dilihat bahwa nilai GCV yang paling minimum adalah nilai GCV dengan tiga titik knot. Setelah didapatkan nilai titik knot yang optimal langakah selanjutnya ialah membuat model regresi nonparametrik yang terbentuk dengan tiga titik knot.

$$
\begin{gathered}
\hat{y}=125,6963-0,2241 x_{1}-0,1658\left(x_{1}-1,3362\right)_{+}+4,4682\left(x_{1}-3,5017\right)_{+}+6,6835\left(x_{2}-8,3507\right)_{+} \\
+0,4837 x_{2}-2,3850\left(x_{2}-6,5645\right)_{+}-7,4978\left(x_{2}-8,8866\right)_{+}-5,1418 x_{a}+8,0445\left(x_{a}-11_{2} 6441\right)_{+} \\
-7,9781\left(x_{a}-12,9545\right)_{+}+6,5148\left(x_{a}-13,3476\right)_{+}+1,5425 x_{4}-1,8786\left(x_{4}-2,2676\right)_{+} \\
-1,4173\left(x_{4}-6,3366\right)_{+}+2,7702\left(x_{4}-7,5572\right)_{+}-1,0291 x_{5}+1,0910\left(x_{5}-63,7907\right)_{+} \\
+1,0588\left(x_{5}-74,0424\right)_{+}-1,6028\left(x_{5}-77,1179\right)_{+}
\end{gathered}
$$

Model regresi nonparametrik spline truncated dnegan tiga titik knot memiliki nilai $\mathrm{R}^{2}$ sebesar $74,48 \%$ hal ini dapat dikatakan bahwa laju pertumbuhan penduduk, rata-rata lama sekolah, angka harapan lama sekolah, tingkat pengangguran terbuka, dan tingkat partisipasi angkatan kerja berpengaruh sebesar 74,48\% terhadap persentase penduduk miskin di Kalimantan sedangkan sisanya sebesar 25,52\% dipengaruhi oleh variabel lain.

\subsection{Pengujian Signifkansi Secara Simultan}

Uji simultan merupakan pengujian parameter model regresi secara bersamaan. Uji ini bertujuan untuk mengetahui parameter model regresi tersebut telah signifikan atau tidak.

Tabel 2 Analisis Varians Model Terbaik

\begin{tabular}{|c|c|c|c|c|}
\hline $\begin{array}{c}\text { Sumber } \\
\text { Variasi }\end{array}$ & $\begin{array}{c}\text { Derajat } \\
\text { Bebas }\end{array}$ & $\begin{array}{c}\text { Jumlah } \\
\text { Kuadrat }\end{array}$ & $\begin{array}{c}\text { Rataan } \\
\text { Kuadrat }\end{array}$ & F hitung \\
\hline Regresi & 20 & 194,81 & 9,74 & \multirow{2}{*}{3,18} \\
\hline Residual & 35 & 107,23 & 3,07 & \\
\hline Total & 55 & 302,13 & & \\
\hline
\end{tabular}

Pada Tabel 2 dapat dilihat bahwa $\mathrm{F}_{\text {hitung }}$ sebesar 3,18. Pada pengujian ini taraf signifikansi adalah 5\% dan $\mathrm{F}$ $0,05(20 ; 35)=1,88$. Berdasarkan nilai $F_{\text {hitung }}$ dan $\mathrm{F}_{0,05(20 ; 35)}$ maka dapat diputuskan tolak $\mathrm{H}_{0}$ karena $\mathrm{F}_{\text {hitung }}(3,18)>\mathrm{F}$ $0,05(20 ; 35)(1,88)$. Sehingga dapat disimpulkan bahwa didalam model ini terdapat parameter yang signifikan.

\subsection{Pengujian Signifikansi Secara Parsial}

\begin{tabular}{|c|c|c|c|c|}
\hline $\begin{array}{c}\text { Titik } \\
\text { Knot } \\
\text { ke-i }\end{array}$ & Variabel & $\begin{array}{c}\text { Parame } \\
\text { ter }\end{array}$ & $t_{\text {hitung }}$ & $p$-value \\
\hline & & $\beta_{0}$ & $2,25 *$ & 0,03 \\
\hline 1,33 & \multirow{4}{*}{$x_{1}$} & $\beta_{1}$ & $-2,11 *$ & 0,01 \\
\hline 3,50 & & $\beta_{2}$ & $-2,06 *$ & 0,04 \\
\hline \multirow{2}{*}{4,15} & & $\beta_{\mathrm{a}}$ & 1,52 & 0,13 \\
\hline & & $\beta_{4}$ & $-1,31$ & 0,19 \\
\hline
\end{tabular}

Pengujian parameter secara parsial bertujuan untuk mengetahui apakah variabel-variabel prediktor berpengaruh secara parsial terhadap variabel respon. Berikut merupakan nilai $t_{\text {hitung }}$ untuk masing-masing variabel.

Tabel 3 Uji Parsial Estimasi Parameter Spline Linear dengan 3 Titik Knot 


\begin{tabular}{|c|c|c|c|c|}
\hline 6,5 & \multirow{4}{*}{$x_{2}$} & $\beta_{5}$ & 0,18 & 0,85 \\
\hline 8,35 & & $\beta_{6}$ & $-0,7827$ & 0,43 \\
\hline \multirow{2}{*}{8,88} & & $\beta_{7}$ & $2,42^{*}$ & 0,02 \\
\hline & & $\beta_{g}$ & $-2,60 *$ & 0,01 \\
\hline 11,64 & \multirow{4}{*}{$x_{2}$} & $\beta_{9}$ & $-2,29$ & 0,20 \\
\hline 12,95 & & $\beta_{10}$ & 1,89 & 0,06 \\
\hline \multirow{2}{*}{13,34} & & $\beta_{11}$ & $-2,14 *$ & 0,03 \\
\hline & & $\beta_{12}$ & $2,47 *$ & 0,03 \\
\hline 2,26 & \multirow{4}{*}{$x_{4}$} & $\beta_{13}$ & $2,60 *$ & 0,01 \\
\hline 6,33 & & $\beta_{14}$ & $-2,67 *$ & 0,01 \\
\hline \multirow{2}{*}{7,55} & & $\beta_{15}$ & $-1,15$ & 0,25 \\
\hline & & $\beta_{16}$ & 1,90 & 0,06 \\
\hline 63,79 & \multirow{4}{*}{$x_{5}$} & $\beta_{17}$ & $-2,65^{*}$ & 0,01 \\
\hline 74,04 & & $\beta_{18}$ & $2,29 *$ & 0,02 \\
\hline \multirow{2}{*}{77,11} & & $\beta_{19}$ & 1,93 & 0,06 \\
\hline & & $\beta_{20}$ & $-2,81 *$ & 0,01 \\
\hline
\end{tabular}

Berdasarkan Tabel 3 dapat dilihat bahwa terdapat 20 parameter yang terbentuk dengan taraf signifikansi sebesar 5\%. Berdasarkan 20 parameter yang terbentuk, terdapat 12 parameter yang signifikan dan 8 parameter yang tidak signifikan. Parameter tersebut tidak signifikan karena nilai $\left|t_{\text {hitung }}\right|<t_{(0,05 ; a 5)}$ dan nilai $p$-value $>\alpha$.

\subsection{Interpretasi Model}

Interpretasi dari model spline terbaik pada persamaan tersebut untuk salah satu variabel prediktor adalah sebagai berikut:

Hubungan antara Persentase Penduduk Miskin $(y)$ terhadap Laju Pertumbuhan Penduduk $\left(x_{1}\right)$ dengan syarat variabel $x_{2}, x_{2}, x_{4}, x_{5}$ dianggap konstan.

$$
\begin{aligned}
& \hat{y}=125,6963-0,2241 x_{1}-0,1658\left(x_{1}-1,3362\right)_{+} \quad+4,4682\left(x_{1}-3,5017\right)_{+} \\
& =\left\{\begin{array}{lc}
125,6963-0,2241 x_{1} & x_{1}<1,3362 \\
125,9178-0,3899 x_{1} & 1,3362 \leq x_{1}<3,5017 \\
110,2715+4,0783 x_{1} & 3,5017 \leq x_{1}<4,1514 \\
125,8347+0,3294 x_{1} & x_{1} \geq 4,1514
\end{array}\right.
\end{aligned}
$$

Pada saat laju pertumbuhan penduduk kurang dari 1,3362\% dan laju pertumbuhan penduduk bertambah $1 \%$ maka persentase penduduk miskin cenderung turun sebesar $0,2241 \%$. Jika laju pertumbuhan penduduk diantara $1,3362 \%$ dan 3,5017\% dan laju pertumbuhan penduduk bertambah $1 \%$ maka persentase penduduk miskin cenderung turun sebesar $0,3899 \%$. Jika laju pertumbuhan penduduk diantara $3,5017 \%$ dan $4,1514 \%$ dan laju pertumbuhan penduduk bertambah sebesar $1 \%$ maka persentase penduduk miskin cenderung naik $4,0783 \%$. Jika laju pertumbuhan penduduk lebih dari atau sama dengan $4,1514 \%$ dan bertambah sebanyak $1 \%$ maka persentase penduduk miskin naik sebesar $0,3294 \%$.

\section{Kesimpulan}

Berdasarkan uraian pada bab-bab sebelumnya maka diperoleh kesimpulan bahwa berdasarkan data yang tersedia, model regresi nonparametrik spline truncated terbaik adalah dengan tiga titik knot dengan nilai Genealized Cross Validation (GCV) sebesar 4,9061 dan $\mathrm{R}^{2}$ sebesar 74,48\%. Hasil pengujian hipotesis model regresi nonparametrik spline truncated pada data Persentase Penduduk Miskin di Kalimantan menunjukkan terdapat 12 parameter yang signifikan dan 8 parameter yang tidak signifikan.

Selain itu, ketika laju pertumbuhan penduduk kurang dari 3,5017\% dan laju pertumbuhan penduduk bertambah $1 \%$ maka persentase penduduk miskin cenderung turun. Namun jika laju pertumbuhan penduduk lebih dari 3,5017\% laju pertumbuhan penduduk bertambah sebesar $1 \%$ maka persentase penduduk miskin cenderung naik

\section{Ucapan Terima Kasih}

Ucapan terimakasih disampaikan kepada reviewer yang telah memberikan masukan yang sangat berarti untuk perbaikan artikel ini. 


\section{Daftar Pustaka:}

[1] Arjun, D.A, Sifriyani dan Syaripuddin. (2019). Analisis Faktor-Faktor yang Mempengaruhi Tingkat Pengangguran Terbuka di Kalimantan Menggunakan Regresi Nonparametrik Spline Truncated. Prosiding Seminar Nasional Matematika dan Statistika, 115-121..

[2] Fitri, N., Sifriyani, dan Desi Yuniarti. (2019). Nonparametric Geographically Weighted Regression dengan Pendekatan Spline Truncated pada Data Produktivitas Tanaman Padi. Prosiding Seminar Nasional Matematika dan Statistika, 98-105..

[3] Millah, J. dan Sifriyani. (2019). Evaluasi Faktor yang Mempengaruhi Laju Pertumbuhan Ekonomi di Kalimantan Menggunakan Regresi Nonparametrik Spline dengan Pembobot Geografis. Prosiding Seminar Nasional Matematika dan Statistika, 122-129.

[4] Hardle, W. (1990). Applied Nonparametric Regression. Berlin: Humboldt University.

[5] Eubank, R.L., dan Thomas, W. (1993). Detecting Heteroscedasticity in Nonparametric Regression. Journal of the American Statistical Association, Vol.1, pp.387-392.

[6] Chapra, S.C. \& Canale, R.P. 1991. Metode Numerik Untuk Teknik dengan Penerapan pada Komputer Pribadi. Universitas Indonesia (UI-Press), Jakarta.

[7] Polanagau, IYAF., Sifriyani, dan Wasono. (2019). Pemodelan Regresi Nonparametrik Spline Truncated dan Aplikasinya Pada Indeks Pembangunan Manusia di Pulau Kalimantan. Prosiding Seminar Nasional Matematika dan Statistika, 130-137. 